\title{
EDUCAÇÃO, POLÍTICAS E GESTÃO PÚBLICA
}

\author{
Education, policies and public management
}

\author{
Rochana Basso $^{1}$; Silvia Regina Canan ${ }^{2}$
}

\author{
${ }^{1}$ Universidade Regional Integrada do Alto Uruguai e das Missões \\ ${ }^{2}$ Universidade Regional Integrada do Alto Uruguai e das Missões. E-mail: silvia@uri.edu.br
}

Data do recebimento: 04/08/2020 - Data do aceite: 14/10/2020

\begin{abstract}
RESUMO: Este artigo, construído a partir de estudos desenvolvidos junto ao NEPPES - Núcleo de Estudos em Políticas e Processos de Educação Superior, no âmbito do Programa de Pós-Graduação em Educação da URI, tem como foco principal a discussão de temáticas ligadas ao processo histórico da educação, suas políticas e a respectiva vinculação ao desenvolvimento do capitalismo neoliberal, origem, ascensão e rupturas possíveis. Trata-se de uma pesquisa teórica para a qual privilegiou-se a pesquisa exploratória, com sistematização das principais ideias dos autores estudados. Também buscou-se apresentar algumas considerações relativas à evolução do processo científico da construção e inserção desses no âmbito educacional. O estudo nos permite afirmar que a temática da educação remete à necessidade de transformação social de modo pleno. A educação precisa ser âncora das mudanças sociais. Para isso, precisa estar articulada e definida no seu inter-relacionamento com as condições sociais, políticas e econômicas.
\end{abstract}

Palavras-chave: Educação. Políticas Públicas. Transformação social.

\begin{abstract}
This article was based in studies developed at NEPPES, which is a Center of Studies in Higher Education Policies and Processes belonging to the Postgraduate Programme in Education at Universidade Regional Integrada do Alto Uruguai e das Missões - URI. The focus of this study is on the discussion of themes related to the historical process of education and its policies and the respective link to the development of neoliberal capitalism, origin, rise and possible ruptures. This is a theoretical research, having the exploratory research as a main tool to systematize the main ideas of the authors studied. Some considerations regarding the evolution of the scientific process of construction and insertion of these in the educational scope were also pre-
\end{abstract}


sented. The study makes possible to state that education is a theme that refers to the need for complete social transformation. Education needs to be taken as an anchor for social changes. For this, education needs to be articulated and defined according to its social, political and economic conditions.

Keywords: Education. Public policy. Social transformation.

\section{Introdução}

Esse artigo tem sua origem da leitura e discussão de textos que abordam a temática educação, construído a partir de estudos desenvolvidos junto ao NEPPES - Núcleo de Estudos em Políticas e Processos de Educação Superior, no âmbito do Programa de Pós-Graduação em Educação da URI, iniciando com considerações sobre a Política Educacional, a partir do que historiciza as questões educativas presentes nos debates políticos nacionais. Na sequência evoca-se a temática das Políticas Públicas, que perpassa todos os níveis e modalidades educacionais indo além dos seus aspectos didáticos e pedagógicos, demonstrando as possibilidades de atuação dos atores sociais e políticos, na área educacional. E pela obviedade, é necessário refletir-se também sobre a Nova Gestão Pública no contexto escolar, especialmente sobre a percepção de diretores escolares em relação às novas demandas sociais, entre essas está a Modernização Administrativa, que chega com o objetivo de dinamizar as práticas dos gestores, direcionando-as sob a óptica da possibilidade da superação da lógica do capital, por meio de processos educativos amplos. Como tópico final, reflete-se sobre a democracia e sua crise, que embora jamais tenha assegurado direitos universais no capitalismo, pode ser vista como uma possibilidade de superação das desigualdades sociais e outras conjecturas presentes no mundo pós-moderno.

\section{Considerações sobre Política Educacional do Brasil}

A temática Política Educacional é uma das questões educativas que ganhou mais destaque nos debates políticos a partir da década de 30, quando se difundiu a ideia de que a educação seria capaz de solucionar problemas de ordem social, econômica e política do país.

Dentre os principais fatos ocorridos na história da educação nacional, a cronologia traz a promulgação da Constituição Federal em 1934, quando o presidente da época, Getúlio Vargas realiza diversas declarações a respeito da educação, enfatizando sua importância na formação política do povo. $\mathrm{Na}$ sequência, em 1937, com a implantação do Estado Novo, a educação tem seu papel definido no projeto de nacionalidade idealizado pelo Estado, com a função de equilibrar a questão social e evitar manifestações ideológicas. Na década de quarenta inicia-se uma reforma, com a implementação das chamadas Leis Orgânicas do Ensino, complementadas em 1945, prevendo a criação do Serviço Nacional de Aprendizagem Industrial (SENAI), Serviço Nacional de Aprendizagem Comercial (SENAC), além de organizar os ensinos primário, secundário e normal, ensino comercial e ensino agrícola (SHIROMA; MORAES; EVANGELISTA, 2007).

Relatos e constatações históricas têm mostrado que as Leis Orgânicas perpetuaram 
um dualismo que ainda hoje não foi resolvido em nível de Brasil, qual seja, aos menos favorecidos economicamente destina-se, de maneira precária e de forma acelerada o ensino fundamental e profissionalizante, uma vez que o mercado de trabalho necessita de mão de obra barata. Àqueles de melhor condição socioeconômica são oferecidos o ensino médio e o superior, permitindo-lhes uma melhor preparação para alçar cargos que necessitam de profissionais mais qualificados.

Shiroma; Moraes e Evangelista (2007) relatam que findados os anos ditatoriais do Estado Novo, foi promulgada a Nova Constituição, com a promessa de liberdade e direito à educação para todos, em todos os níveis, conforme pregava a Carta de 1946. Em 1948 uma comissão de especialistas elaborou e enviou ao Congresso Nacional uma proposta sobre os novos rumos da educação brasileira. Os debates duraram até 1961 e terminaram na promulgação da Lei de Diretrizes e Bases da Educação Nacional, Lei 4.024, de 20 de dezembro daquele ano. Nos anos de 1960 e 1970, o então presidente da república João Goulart, propôs o Plano Nacional de Alfabetização (PNA), inspirado no método Freiriano, visando aumentar o número de eleitores, uma vez que o voto não era facultativo aos analfabetos. Entretanto, com o golpe militar em abril de 1964, uma das primeiras ações do governo foi extinguir o PNE. As reformas que vieram a partir do golpe tinham claramente o objetivo de formar capital humano para o mercado de trabalho, estimular hábitos de consumo, total controle sobre a produção intelectual, cultural e artística, além de integrar a educação aos planos de desenvolvimento e segurança nacionais. A criação do Plano Decenal de Desenvolvimento Econômico e Social (1967-1976), planejado por economistas, estampa exatamente essa visão de que a educação deve acelerar o processo de desenvolvimento econômico do país, formando cidadãos aptos a produzir lucros individuais e sociais. Em 1967 foi promulgada a Constituição, que não previa percentuais mínimos a serem destinados à educação.

Na década de 1970, a crise econômica foi instaurada e o regime militar, pressionado. A educação, então, foi incluída nas políticas sociais e surge o Plano de Desenvolvimento Econômico (PDE), com programas e ações voltados à população mais carente. Assim, a educação começa ter o papel de formar o cidadão para o mercado de trabalho, e passa a ser encarada como a chave para a diminuição das desigualdades sociais. Em 1979, com a anistia decretada, muitos intelectuais retornaram ao Brasil e reforçaram movimentos oposicionistas, preocupados com os rumos sociais, políticos e educacionais do país. No final de 1985, o regime militar deu lugar à "Nova República" (SHIROMA; MORAES; EVANGELISTA, 2007).

As lutas dos educadores eram pela criação de um sistema nacional de educação, com educação pública e gratuita como direito de todos e dever do Estado. Depois de um longo tempo de discussões, foi aprovada a Lei de Diretrizes e Bases da Educação Nacional (LDBEN), porém este projeto acabou não atendendo às expectativas da comunidade acadêmica. E no campo da economia os governantes dos anos de 1990, tentam sair da crise econômica que foi instaurada nos anos 1980, no Brasil e em outras partes do planeta. Nos anos seguintes é possível constatar que a qualificação profissional dos trabalhadores ganha papel de destaque no cenário mundial da educação e passa-se a acreditar que o cidadão do século XXI precisava dominar os códigos da modernidade. Assim, nesse contexto, a educação passa a ser a peça chave que vai resolver essa questão da competitividade. É a partir dessa realidade econômica, política e social que várias organizações, entidades e agências multilaterais passam a se interessar pela educação e começam a realizar estudos e levantamento de dados, que dão origem 
a documentos, propostas e orientações de como países da América Latina e Caribe devem pensar e definir suas políticas públicas voltadas à educação de seus países. Outras contextualizações seriam possíveis, porém limita-se a estas indicadas, cabendo dizer que a política nacional de educação é muito mais do que legislações propostas, muitas vezes, por pessoas que são externas ao ambiente educacional, além de ser extremamente afetada por questões financeiras, deixando claro que historicamente a educação pública de qualidade não tem sido prioridade, permitindo questionar-se sobre a ação efetiva de alguns órgãos multilaterais que norteiam a educação nacional e os países da América Latina e Caribe nos dias de hoje.

\section{Políticas Educacionais e Gestão Pública}

Avançando na temática das Políticas Públicas no campo educacional, são trazidas as contribuições de Boneti (2006) que faz uma análise dos resultados de sua aplicação e do gerenciamento dos recursos públicos, com abordagem da gênese e trajetória da política, transitando pela instância burocrática, até a sua operacionalização frente aos determinantes políticos e econômicos que exercem impacto decisivo sobre elas.

Para Boneti (2006) o Estado não é uma instituição neutra, movida por valores éticos, políticos e culturais, mas é o produto de forças entre setores da sociedade civil, afirmando que é na relação entre Estado, classes sociais e sociedade civil que surgem os agentes definidores das políticas públicas. E avança dizendo que a gênese de uma política pública não está na sua origem em si, ou seja, no momento em que ela é planificada, escrita, mas antes disso há um processo que a origina, processo que é permeado por determinantes econômicos sociais e políticos e que se fun- damenta em alguns referenciais que vão do tradicionalismo iluminista, passando pelo etnocentrismo, pelos princípios da termodinâmica, pela universalidade e infalibilidade das ciências até o caráter utilitário da ciência que está associado ao etnocentrismo. $\mathrm{O}$ autor reporta a questão social como um desafio na construção de ações públicas mínimas para preservar a coletividade, sendo o setor social o que primeiro padece em momentos de transição ou crise.

Para Boneti (2006) as políticas públicas na contemporaneidade são marcadas pelo processo de reestruturação produtiva em escala global, caracterizada por uma economia que funciona em tempo real em escala planetária e que trouxe com nitidez a diferenciação entre trabalho e emprego. O impacto dessa nova configuração nas políticas públicas não é pequeno, ele vem desde o papel do Estado até o perfil de pessoa que se quer obter para atuar no novo contexto. Trata-se de uma correlação de forças não só nos limites nacionais, mas também internacionais.

E nesse contexto é possível afirmar por exemplo, que os movimentos sociais se diferem daqueles do passado, cujo objetivo era comum a uma classe; hoje, esses movimentos são singulares, de interesses individuais e ligados a problemáticas como a fome, o gênero, a questão do negro, entre outros, e direta ou indiretamente influenciam na definição das políticas públicas. E para Boneti (2006) não é possível separar o Estado da sociedade civil, visto que não existe mais tal dicotomia, pois os movimentos da sociedade civil organizada não são mais um mecanismo somente das camadas populares, mas também das classes dominantes.

As novas configurações contemporâneas econômicas e sociais alcançaram o contexto escolar sendo necessário inteirar-se da percepção dos diretores escolares em relação às novas demandas sociais e as políticas públicas em educação no Brasil, a partir da 
Constituição Federal de 1988, considerada o marco principal de mudança nessas políticas, uma vez que visa promover o fortalecimento dos governos locais como resultado das pressões de movimentos que demandavam maior descentralização e redemocratização da sociedade ensejando novos modelos de gestão das políticas públicas no país e a consequente cobrança ao Estados de maior transparência e prestação de contas. Desse modo, a consequência em cadeia do melhoramento estrutural das políticas públicas, refletiria igualmente nas políticas educativas.

A Nova regulação nas políticas educativas tem interferido na organização e gestão da educação, passando pelas várias mediações dos sistemas educacionais (principalmente na escola). Está centrada na avaliação externa, articulando seus resultados à gestão escolar e ao financiamento da educação pela figura da Nova Gestão Pública (NGP) (OLIVEIRA; DUARTE; CLEMENTINO, 2017).

De acordo com Oliveira; Duarte e Clementino (2017) as bases da NGP trazem uma crítica ao Estado de Bem-Estar Social, ao planejamento centralizado e ao papel indutor e promotor do bem social exercido preponderantemente pelo Estado, e suas bases epistemológicas estão no Novo Institucionalismo (onde as instituições afetam o comportamento de atores sociais). A NGP se instala como inovação, criticando a burocratização dos Estados de Bem-Estar Social promovendo ataques às hierarquias, à centralização do poder e das decisões, à rigidez das estruturas governamentais. O funcionalismo passa a ser altamente criticado como ineficiente e pouco comprometido, o que o coloca no centro dos ataques ao modelo de organização estatal.

Oliveira; Duarte e Clementino (2017) alertam que a aplicação da NGP alterou de maneira drástica a forma como se concebe a governança das instituições educativas, já que princípios como a autonomia escolar, a prestação de contas, a gestão baseada em resultados e a liberdade de escolha escolar têm penetrado profundamente em como se regulam, proveem e financiam os serviços educativos. Ao mesmo tempo que as escolas passaram a ter maior autonomia por meio da gestão democrática, passaram a conviver com estratégias e ferramentas de controle e regulação por meio da avaliação externa com vistas à maior eficiência nos resultados. Como exemplo podemos citar os modelos da "Qualidade Total" e parcerias empresa e escola, entre outros.

Entretanto, gestões/diretores atuam no limite da relação entre os recursos disponíveis e as condições objetivas para a oferta educacional. A principal queixa se relaciona às condições objetivas para o desenvolvimento do trabalho pedagógico e à insuficiência de funcionários para atender a demanda, com impacto direto no trabalho dos professores e em sua satisfação profissional e, consequentemente, colocam os diretores no centro do conflito: ante a comunidade escolar, que busca resposta às suas necessidades e diante do poder público, que não atende com eficiência às demandas e exige o cumprimento das metas preestabelecidas (OLIVEIRA; DUARTE; CLEMENTINO, 2017)

No cotidiano escolar, constata-se que a gestão se dá de modo compartilhado, embora a maior carga de trabalho e responsabilidade recaia sobre a direção. Há certo grau de autonomia para tomar decisões, porém recebem dos órgãos competentes orientações determinadas, que limitam seu campo de ação reforçado pelo número insuficiente de funcionários. Contudo, criam-se, porém, estratégias pedagógicas para fazer com que os estudantes tenham um bom desempenho nos testes e, assim, as escolas possam atingir suas metas, mesmo que, às vezes, deslocando o foco do projeto pedagógico, sobretudo pelo desejo de fazer algo diferente pela melhoria da escola, a partir de suas insatisfações como docentes, sobretudo no que tange às condições de tra- 
balho e à qualidade do ensino (OLIVEIRA; DUARTE; CLEMENTINO, 2017)

Por fim, é possível perceber que ocorreram mudanças no perfil da direção escolar, transitando de um tipo técnico e burocrático para uma liderança política ou gerencial. E que, a necessidade de corresponder às expectativas do corpo docente, discente e da administração tem implicado sobrecarga de trabalho desses profissionais. Houve um redesenho da gestão escolar com a introdução da NGP e que isso carece de maiores estudos, tendo em vista a diversidade de respostas e situações novas que são geradas por parte dos próprios sujeitos envolvidos, devendo-se levar em conta as especificidades locais, regionais e nacionais, compreendendo em que medida podem configurar-se como tendência internacional. O que se percebe, ainda que de maneira subliminar é que os princípios de eficiência importados da iniciativa privada vão sendo naturalizados pela escola como valores universais, como reflexo da modernização administrativa que repercute também na gestão educacional.

Oportuno, nessas circunstâncias, refletir dialeticamente, como propõe Mészáros (2008) sobre o fortalecimento da determinação dos que lutam contra o domínio do capital, a exploração e a opressão, sobretudo no campo do trabalho e a possibilidade da superação da lógica do capital, por meio de processos educativos amplos, nos quais se anuncia a instauração de uma sociedade para além do capital.

Segundo Mészáros (2008, p. 27), são infrutíferas as reformas que apenas se propõem a correções marginais, mantendo intactas as estruturas fundamentais da sociedade e conformando-se às exigências da lógica do capital, pois essa modalidade utiliza-se das reformas educacionais para apenas remediar os efeitos da ordem produtiva, mas não elimina os "fundamentos causais e profundamente enraizados". Para o autor, "limitar uma mudança educacional radical às margens corretivas interesseiras do capital significa abandonar de uma só vez, conscientemente ou não, o objetivo de uma transformação social qualitativa".

O autor reconhece que a educação institucionalizada serviu, nos últimos 150 anos, para fornecer condições técnicas e humanas à expansão do capital, ao mesmo tempo em que contribuiu para instalar valores que legitimam os interesses dominantes e que negam alternativas possíveis a esse modelo. A criação de estratégias para o rompimento do controle exercido pelo capital está na busca de soluções não apenas na dimensão formal, mas no que é essencial. Ainda afirma que, não basta simplesmente reformar o sistema escolar formal estabelecido, porque isso traduziria apenas uma mudança institucional isolada. "O que precisa ser confrontado é todo o sistema de internalização, com todas as suas dimensões, visíveis e ocultas" (MÉSZAROS, 2008, p. 47).

A internalização, entendida como o esforço do capital em fazer com que cada indivíduo incorpore como suas as metas de reprodução do sistema, legitimando sua posição na hierarquia social e conformando suas expectativas e sua conduta ao estipulado pela ordem estabelecida, insere-se como instrumento que conforma a totalidade das práticas sociais, entre elas, a educação, ao interesse do capital.

Para Mészaros (2008, p. 57) é preciso: "Romper com a lógica do capital na área de educação equivale, portanto, a substituir as formas onipresentes e profundamente enraizadas de internalização mistificadora por uma alternativa concreta abrangente". Prossegue afirmando que a educação, reconhecida, no seu entendimento amplo, é um processo contínuo de aprendizagem. Assim é preciso fazer uma reforma, que segundo o autor, significa desafiar as formas atualmente dominantes de internalização existentes no sistema educa- 
cional formal, pôr em execução urgentemente uma atividade de "contrainternalização" coerente e sustentada na direção da criação de uma alternativa ao que já existe. A educação formal precisa desatar-se do revestimento da lógica do capital e mover-se em direção a práticas educacionais mais abrangentes.

Para esse fim, a universalização da educação e do trabalho são peças fundamentais, sem as quais não pode haver solução para a auto alienação do trabalho, uma vez que a educação para além do capital almeja uma ordem social qualitativamente diferente.

No processo histórico, onde percebe-se a crise estrutural do capital global, define-se também um espaço histórico e social aberto à ruptura com a lógica do capital e à elaboração de planos estratégicos na direção de uma educação para além do capital. Nesse ambiente, a tarefa educacional é uma tarefa de transformação social, ampla e emancipadora. A educação deve ser articulada e redefinida no seu inter-relacionamento com as condições cambiantes e as necessidades da transformação social emancipadora e progressiva em curso, ou seja, indica a necessidade de rupturas, como aquela proposta por Castells (2018).

Castells (2018), ao analisar os fatores da crise da democracia liberal, indica que a gênese está na crise do Estado-Nação provocada pelo processo de globalização da economia e pelo desenvolvimento das tecnologias da informação a partir dos anos 1970; na falta de uma identidade comum entre os países membros, a qual levaria à formação de uma "autodefinição por exclusão do outro"; na ausência de participação social na construção da instância supranacional e o aumento ainda maior do distanciamento entre os cidadãos e os seus governos.

Outro elemento chave da crise da democracia liberal, segundo Castells (2018), está no atual modelo de acumulação de capitais.
Sustentado por ciclos de especulação financeira e pela ideologia neoliberal, este modelo vem se reproduzindo à custa do desemprego de milhares de pessoas, do endividamento de famílias, da expropriação da natureza, da violação de direitos humanos, entre outros. Isso conduz ao convencimento de que o Estado não deve intervir nos mercados, quando na realidade em todos os cantos da Europa o que se viu foi o alinhamento dos governos e da União Europeia ao mercado financeiro e a imposição de políticas de austeridade fiscal para sair da crise. Para o autor essa seria a falácia da ideologia neoliberal proposta.

Nesse processo fica evidente a profunda divisão de classe, raça e cultura que define as sociedades ocidentais e que ameaça a democracia, uma vez que a universalização da "cidadania europeia" não é praticada pela maioria das pessoas (CASTELLS, 2018, p. 66).

Contudo, outro ponto comum da crise de legitimidade política é o que pode levar à emergência de novos atores políticos, que organizam suas práticas a partir de valores progressistas alternativos e reivindicam a democracia em suas próprias práticas. Aqui é importante observar como o contexto social, político e econômico é determinante para a emergência dessa forma de ação política.

A democracia está em crise e certamente precisa ser reinventada, entretanto, resta a utopia de que embora a democracia jamais tenha assegurado direitos universais no capitalismo, é só nela que se torna possível superar a alienação política e enfrentar as desigualdades sociais.

\section{Considerações Finais}

Com relação à temática políticas públicas em educação e de formação de professores, sintetizada em seu processo histórico da 
elaboração da política educacional no Brasil, fica claro que a educação pública de qualidade não era prioridade no período histórico retratado no decorrer desse artigo; bem como, instiga a questionar sobre a ação de alguns órgãos multilaterais que norteiam a educação nacional e os países da América Latina e Caribe quando a sua efetiva contribuição na implantação de políticas públicas em nível local, regional e mundial.

Quando as políticas públicas tornam-se um fato político, é possível afirmar que as influências dos agentes definidores são contundentes, embora veladas, sendo que a questão central de todo esse caminhar da política é saber se o grupo social de onde se originou a política está bem representado politicamente nas instâncias por onde ela passa, não separando assim, Estado e sociedade civil, visto que não existe mais tal dicotomia, pois os movimentos da sociedade civil não são mais um mecanismo somente das camadas populares, mas também das classes dominantes.

Vinculada às políticas públicas está, no contexto escolar, a nova gestão pública que aponta para mudanças no perfil da direção escolar, transitando de um tipo técnico e burocrático para uma liderança política ou gerencial, provocando um redesenho da gestão escolar com a introdução da Nova Gestão
Pública que prescinde de maiores estudos, tendo em vista a diversidade de respostas e situações novas que são geradas por parte dos próprios sujeitos envolvidos. O certo é que a NGP vai sendo assimilada pelos gestores da educação pública, do MEC às escolas, perseguindo um Estado supostamente eficiente e dinâmico que busca fazer mais com menos.

É nesse contexto que surge a modernização administrativa, cuja repercussão recai sobre a gestão educacional que precisa se adequar ao processo para que não fique a parte da suposta evolução da educação nacional, regrada por leis que, numa leitura mais aprofunda percebe-se uma incompletude nas ações que legalmente são propostas. $\mathrm{O}$ desfecho de todo o processo educacional, tem como pano de fundo a crise estrutural do capital em nível mundial, que traz características de ruptura com a lógica capitalismo da acumulação e do lucro exacerbado.

Por fim, pode-se afirmar que a tarefa educacional indica a necessidade de transformação social, ampla e emancipadora. A educação deve ser articulada e redefinida no seu inter-relacionamento com as condições sociais, políticas e econômicas, razões para uma transformação social tendo como âncora a educação.

\section{REFERÊNCIAS}

BONETI, L.W. Políticas Públicas por Dentro. Ijuí/RS: Editora UNIJUI, 2006.

CASTELLS, M. Ruptura: a crise da democracia liberal. Rio de Janeiro/RJ: Zahar Editores, 2018. MÉSZÁROS, I. Educação para além do capital. 2. ed. São Paulo/SP: Boitempo Editorial, 2008. OLIVEIRA, D.A.; DUARTE, A.W.B.; CLEMENTINO, A.N. A Nova Gestão Pública no contexto escolar e os dilemas dos(as) diretores(as). Revista Brasileira de Política e Administração da Educação, v. 33, n. 3, p. 706-726, 2017.

ShIROMA, E.O.; MORAES, M.C.M.; EVANGELISTA. O. Política Educacional. 4. ed. Rio de Janeiro/RJ: Editora Lamparina, 2004. 